Arq. Bras. Med. Vet. Zootec., v.66, n.5, p.1339-1342, 2014

\title{
Pleuris associada à criptococose em cão: relato de caso
}

\author{
[Pleurisy associated with cryptococcosis in a dog: case report] \\ V.L. Souza ${ }^{1}$, C.V.S. Brandão ${ }^{3}$, B.W. Minto ${ }^{2}$, C.A. Estanislau ${ }^{3}$, J.J.T. Ranzani ${ }^{3}$, V.R. Babicsak ${ }^{3}$, \\ M.J. Mamprim ${ }^{3}$, N.S. Rocha ${ }^{3}$, M.G. Ribeiro ${ }^{3}$ \\ ${ }^{1}$ Aluno de pós-graduação - FMVZ - UNESP Campus de Botucatu - SP \\ ${ }^{2}$ FCAV - UNESP - Campus de Jaboticabal - Jaboticabal, SP \\ ${ }^{3}$ FMVZ - UNESP - Campus de Botucatu - Botucatu, SP
}

\section{RESUMO}

A Criptococose é uma importante doença infecciosa fúngica, causada por uma levedura do gênero Cryptococcus, que acomete diferentes espécies inclusive o homem. Há poucos relatos na literatura sobre a criptococose pulmonar em cães. O presente trabalho relata um caso de criptococose em um cão apresentando alterações respiratórias, especialmente dispneia. O diagnóstico foi realizado por meio da citologia aspirativa, após toracotomia exploratória, sendo observado um quadro de pleuris grave. O paciente foi tratado durante 90 dias com itraconazol e apresentou, ao final do tratamento, a remissão completa dos sintomas relatados.

Palavras-chave: cão, criptococose, pleurite, zoonose

\begin{abstract}
Cryptococcosis is a major infectious disease caused by a yeast from the Cryptococcus genre which affects different species including humans. There are few reports related to pulmonary cryptococcosis in dogs. A case of Cryptococcosis in a dog showing dyspnea was described. The diagnosis was done by aspiration cytology after exploratory thoracotomy, and a picture of severe pleurisy was observed. The diagnosis was done by needle aspiration cytology after thoracotomy. Severe pleuris frame was observed. Treatment with itraconazole was performed for 90 days, and at the end of the treatment the dog presented complete remission of reported symptoms.
\end{abstract}

Keywords: dogs, cryptococcosis, pleuritis, zoonosis

\section{INTRODUÇÃO}

A criptococose é uma doença fúngica sistêmica causada por um microorganismo leveduriforme conhecido como Cryptococcus neoformans. O gato é a espécie mais afetada, porém é descrita também nos cães, equinos, bovinos (Nelson e Couto, 2006), inclusive no homem, sendo fundamentalmente uma infecção oportunista (Lacaz et al., 2002).

Cryptococcus neoformans é um micro-organismo cosmopolita (Malik et al., 2006), transmitido principalmente por inalação dos esporos, e sua deposição ocorre no trato respiratório (Pereira e Coutinho, 2003; Honsho et al., 2003).

Recebido em 8 de maio de 2013

Aceito em 19 de fevereiro de 2014

E-mail: vivianlsouza@hotmail.com
Especificamente em relação aos cães com criptococose, na maioria dos relatos, são observados sinais clínicos neurológicos e/ou oftálmicos (Larsson et al., 2003; Beheregaray et al., 2005). O trato respiratório superior em cães também pode ser envolvido, entretanto os relatos quanto a essas alterações e alterações do trato respiratório inferior ainda são escassos na literatura.

O tratamento de cães acometidos pela doença tem sido realizado com medicações antifúngicas, como anfoterecina B, cetoconazol, itraconazol, fluconazol isoladamente e em várias combinações, e os animais devem ser tratados até que estejam clinicamente normais (Nelson e Couto, 2006). 


\section{CASUÍSTICA}

Foi atendido um animal da espécie canina, raça Blue Heeler, fêmea, pesando $15,6 \mathrm{~kg}$, com seis anos de idade e histórico de dispneia havia uma semana. O proprietário relatou que o animal estava sendo tratado por outro Médico Veterinário para erliquiose canina com doxiciclina (100mg/BID) e que recentemente havia sido tratado para pneumonia com sulfametaxozol e trimetoprima (Bactrim ${ }^{\circledR}$, Roche, Brasil). Referiu ainda aquesia havia cinco dias, urina de coloração escura, hiporexia e oligodipsia. $\mathrm{O}$ animal estava vacinado $\mathrm{e}$ vermifugado adequadamente, possuía quatro contactantes hígidos, e até o momento da consulta não havia qualquer histórico de trauma.

Ao exame físico, o paciente apresentou-se com mucosas hipocoradas, hidratação adequada, gravemente dispneico, temperatura de $39,6^{\circ} \mathrm{C}$ e linfonodos sem qualquer alteração digna de nota. $\mathrm{Na}$ auscultação cardiopulmonar, foi observado roce pleural e exacerbação dos sons cardíacos e ainda sensibilidade à palpação abdominal.

Foram realizados exames laboratoriais de sangue (hemograma e bioquímico para avaliação hepática e renal). Foram realizados exames radiográficos do tórax e abdômen, sendo visibilizada uma opacificação em hemitórax esquerdo, discretas áreas circunscritas gasosas em sobreposição, deslocando a traqueia e a silhueta cardíaca dorsalmente, padrão pulmonar alveolar em lobo médio direito, áreas circunscritas radioluscentes em lobo cranial direito, e alteração da forma da crura diafragmática, sendo assim sugestivo de efusão pleural ou massa torácica. No abdômen foi visibilizada discreta dilatação gástrica por conteúdo gasoso.

O líquido torácico foi drenado e encaminhado para análise laboratorial e citológica, sendo observada alta celularidade composta de $100 \%$ de neutrófilos segmentados, discretamente degenerados, e exsudato neutrofílico não séptico.

Realizou-se fluidoterapia intravenosa, bem como administração de ceftriaxona (30mg/kg/IV), metronidazol $(25 \mathrm{mg} / \mathrm{kg} / \mathrm{IV})$ e enrofloxacina $(7,5 \mathrm{mg} / \mathrm{kg} / \mathrm{SC})$. Foi prescrito dipirona $(25 \mathrm{mg} / \mathrm{kg} / \mathrm{VO})$ e retorno para o próximo dia. No dia seguinte, o proprietário não relatou melhora do quadro clínico, e o paciente ainda se apresentava intensamente dispneico. As medicações anteriores foram re-administradas.

O paciente foi encaminhado para tomografia computadorizada (TC) do tórax, sendo observado um aumento do coeficiente de atenuação dos lobos pulmonares esquerdos, evidenciando-se a presença de broncogramas aéreos, sugerindo consolidação por atelectasia pulmonar. Observou-se ainda conteúdo de atenuação líquida e discreta coleção gasosa ocupando toda a extensão do hemitórax esquerdo, medindo cerca de $27,0 \mathrm{~cm}$ de comprimento $\mathrm{x} 10,8 \mathrm{~cm}$ de largura $\mathrm{x} 12 \mathrm{~cm}$ de altura, envolvido pela pleura com homogênea e moderada intensificação de contraste. Foram observados lobos pulmonares esquerdos consolidados, sendo, por fim, sugestivo de derrame pleural em hemitórax esquerdo. Posteriormente, o animal foi encaminhado para o centro cirúrgico para realização de toracotomia exploratória. $\mathrm{O}$ animal foi posicionado em decúbito lateral direito, sendo realizada toracotomia exploratória no oitavo espaço intercostal esquerdo. Neste verificou-se grande quantidade de líquido serosanguinolento, sendo drenado para permitir melhor visualização dos lobos pulmonares. Os lobos pulmonares esquerdos apresentavam-se recobertos por grande quantidade de material fibrinoide com alteração de todo seu parênquima, o que impedia a expansão pulmonar. Com auxílio de pinças hemostáticas, o material foi retirado do pulmão e encaminhado para análise citopatológica. Foi realizada a abertura do mediastino e remoção de parte do material fibrinoide, permitindo, assim, uma maior expansão dos lobos pulmonares direitos. Em seguida, realizou-se sutura da cavidade torácica e colocação de um dreno torácico para drenagem de toda secreção e/ou ar livre presente na cavidade. Após a cirurgia, o animal foi mantido sob monitorização intensa, sendo observada melhora no padrão respiratório.

O diagnóstico obtido pelo exame citopatológico foi de criptococose. $\mathrm{O}$ material foi encaminhado para análise. $\mathrm{O}$ cultivo aeróbico foi positivo para Micrococcus sp e Staphylococous sp; e negativo para Cryptococcus sp $e$ citologia positiva para Cryptococcus sp.

Foi prescrito itraconazol (10mg/kg/BID/7d) e, após esse período, $5 \mathrm{mg} / \mathrm{kg} / \mathrm{BID} / 90 \mathrm{~d}$, além de medicação protetora hepática (silimarina - 
$50 \mathrm{mg} / \mathrm{kg} / \mathrm{BID}$ ). O animal retornou no segundo dia pós-operatório com significativa melhora do estado geral. O proprietário relatou que o animal estava mais ativo, com normorexia, normodipsia, urina e fezes em coloração e quantidade normais, um padrão respiratório melhor. Foram realizadas medicações por via intravenosa e foram drenados $130 \mathrm{~mL}$ de secreção sanguinolenta torácica. No terceiro dia pós-operatório, o proprietário referiu melhora progressiva do quadro respiratório, mencionando apenas tosse seca, além de estar realizando medicações conforme prescritas. Nesse dia, foram drenados $60 \mathrm{~mL}$ de líquido torácico.

Foram realizados mais três retornos e em todos foi drenada secreção torácica;, no quarto dia foram drenados $40 \mathrm{~mL}$, no quinto dia, $25 \mathrm{~mL}$ e, no sexto dia, $17 \mathrm{~mL}$ de líquido torácico. No sétimo dia pós-operatório, foram drenados apenas $9 \mathrm{~mL}$ de secreção, sendo, assim, retirado o dreno torácico. No décimo dia pós-operatório, foi realizada a retirada dos pontos e coletado sangue para hemograma controle. No décimo terceiro dia pós-operatório, o proprietário relatou diminuição da tosse e melhora significativa do quadro respiratório. $\mathrm{O}$ exame físico apresentouse dentro dos padrões da normalidade, sendo observada apenas crepitação pulmonar leve e, nesse momento, houve normalização do leucograma.

No vigésimo sétimo dia, o proprietário referiu melhora completa com retorno às atividades diárias exercidas pelo animal. Nesse mesmo dia, foi realizado exame radiográfico, sendo observada evolução favorável dos achados radiográficos comparados ao exame anterior; logo, recomendou-se manter as medicações anteriormente prescritas.

Aos 70 dias após a cirurgia, o proprietário relatou ótimo estado geral do animal sem nenhuma alteração digna de nota. Ao exame radiográfico, observou-se presença de incisuras interlobares e retração dorsal dos lobos pulmonares, evidenciando discreta efusão pleural, assim como retração do hemitórax esquerdo. O quadro era favorável em relação aos exames anteriores.

\section{DISCUSSÃO}

Estudos mostram que são raros os casos de criptococose pulmonar em cães, sendo a grande maioria desses relacionada a alterações do sistema nervoso central (Honsho et al.,2003). Além disso, nenhum relato de pleuris foi encontrado na literatura pesquisada.

Em um estudo retrospectivo, McGill et al. (2009) observaram que, depois de 155 animais diagnosticados com criptococose, 72 eram gatos, 57 cães, 20 cavalos, três alpacas, dois furões e uma ovelha. Nesse mesmo estudo, observaram que a localização anatômica nos cães era de doença sino-nasal isolada ou com extensão aos tecidos adjacentes (a doença frequentemente progrediu para trato respiratório inferior), sendo observado um caso de nódulo cutâneo e outros casos de envolvimento do sistema nervoso central. Lester et al. (2004) avaliaram 38 casos de criptococose, sendo $15(39,5 \%)$ em cães. Dentre estes, $9(60 \%)$ apresentaram sinais neurológicos, $2(13,3 \%)$, alterações oculares, e $3(20 \%)$, sinais de trato respiratório superior.

McGill et al. (2009) observaram que 53,6\% dos animais eram fêmeas e a idade dos cães acometidos variou entre 11 meses e 12 anos, com média de 2,5 anos, sendo os animais em sua maioria jovens adultos, semelhante ao presente caso, que se trata de uma fêmea de meia-idade. Os autores relataram ainda que, dos cães avaliados, oito eram de pequeno porte, 23 de médio porte e 24 de grande porte, sendo o animal do presente relato um cão de médio porte.

Observou-se, neste caso, que o animal mantinha contato com aves e que, nas propriedades vizinhas, era utilizada cama de frango na alimentação de bovino. Tal informação assemelha-se ao descrito na literatura, uma vez que o isolamento do agente dá-se, principalmente, a partir de solo rico em excretas de aves (Larsson et al., 2003; Pereira e Coutinho, 2003).

Exames laboratoriais (hemograma e bioquímicos) não foram conclusivos, ou seja, inespecíficos, de acordo com os dados reportados por Nelson e Couto (2006) e Queiroz et al. (2008). 
A cultura micológica para Cryptococcus sp foi negativa em nosso relato, justificada pelo técnico do laboratório responsável pela cultura, devido à intensa quantidade de contaminação bacteriana na amostra e ao efeito residual de algum fármaco que pode ter interferido na cultura.

Martins et al. (2008) concluíram que a citologia aspirativa por agulha fina (CAAF) mostrou-se uma alternativa rápida e eficaz para $\mathrm{o}$ reconhecimento in vivo de estruturas fúngicas como Cryptococcus sp, informação esta similar ao observado neste estudo, no qual a citologia associada à toracotomia pôde confirmar a presença da doença.

Larsson et al. (2003) realizaram o tratamento de um cão com acometimento oftálmico e dermatológico secundário à criptococose por nove meses com itraconazol, observando involução total do quadro sem qualquer efeito adverso ao fármaco.

Até o presente momento pós-operatório, o paciente em questão apresentou evolução favorável, não sendo observado nenhum efeito colateral em relação à droga instituída no tratamento.

\section{CONCLUSÃO}

A toracotomia exploratória associada à $\mathrm{CAAF}$ foi essencial para que se chegasse a um diagnóstico, uma vez que exames radiográficos não foram precisos. Além disso, a toracotomia permitiu a abertura do mediastino, o que facilitou a expansão dos lobos pulmonares direitos, que ainda apresentavam um parênquima viável. Apesar da cultura negativa, o exame citopatológico por aspiração com agulha fina pôde confirmar a doença, o que mostra a importância do exame.

\section{REFERÊNCIAS}

BEHEREGARAY, W.K.; PÖPPL, A. G.; HARTFELDER, C. C. et al. Criptococose em um cão com envolvimento de linfonodos, pele, olhos e glândula mandibular. Rev. Univ. Rural - Série Cienc. Vida, v.25, p.252-253, 2005.

HONSHO, C.S.; MINE, S.Y.; ORIA, A.P. et al. Generalized systemic cryptococcosis in a dog after immunosuppressive corticotherapy. Arq. Bras. Med. Vet. Zootec., v.55, p.155-159, 2003.

LARSSON, C.E.; OTSUKA, M.; MICHALANY, N.S. et al. Criptococose canina: relato de caso. Arq. Bras. Med. Vet. Zootec., v.55, p.533-538, 2003

LACAZ, C.S.; PORTO, E.; MARTINS, J.E.C. et al. Tratado de Micologia Médica. 9.ed. São Paulo: Sarvier, 2002. 1104p.

LESTER, S.J.; KOWALEWICH, N.J.; BARTLETT, K.H. et al. Clinicopathologic features of an unusual outbreak of cryptococcosis in dogs, cats, ferrets, and a bird: 38 cases. J. Am. Vet. Med. Associat., v. 225, p.1716-1722, 2004.

MALIK, R.; KROCKENBERGER, M.; O'BRIEN C.R. et al. Cryptococcosis. In: GREENE, C.E. (eds). Infect. Dis. Dog Cat. Philadelphia: Saunders, 2006. p.584-598.

MARTINS, D.B.; BARBOSA, A.L.T.; CAVALHEIRO, A.C. et al. Diagnóstico de criptococose canina pela citologia aspirativa por agulha fina. Cienc. Rural, v.38, p.826-829, 2008.

McGILL, S.; MALIK, R.; SAUL, N. et al. Cryptococcosis in domestic animals in Western Australia: a retrospective study from 1995 - 2006. Med. Mycol., v.47, p.625-639, 2009.

NELSON, R.W.; COUTO, C.G. Doenças Micóticas Polissistêmicas. In: NELSON, R.W.; COUTO, C.G. (eds.). Medicina Interna de Pequenos Animais. 3.ed., Rio de Janeiro: Elsevier, 2006. p.1249-1257.

PEREIRA, A.P.C.; COUTINHO, S.D.A. Criptococose em cães e gatos - revisão. Ver. Clin. Vet., v.8, p.24-32, 2003.

QUEIROZ, J.P.A.F.; SOUSA, F.D.N.; LAGE, R.A. et al. Criptococose - Uma revisão bibliográfica. Acta Vet. Bras., v.2, p.32-38, 2008. 